\title{
ECONOMIC EVALUATION IN THE AGE OF UNCERTAINTY
}

Giuseppe Pennisi

Advanced School of Public Administration, Rome, Italy

Pasquale L. Scandizzo

University of Rome, Tor Vergata, Italy

Supporting value judgements about policies and programmes is a central task in evaluation. There is, however, little consensus on how evaluators are to accomplish this task. The traditional cost-benefit approaches were found wanting and yet valuation as promoted by checklists or qualitative stakeholder interviews is not anchored to an economic theory and thus inspires little confidence. While no single methodology is likely to be accepted by all, recent developments in economic theory support a new interpretation. This proposed approach is a variant of social cost benefit analysis (SCBA); it retains the representation of stakeholder values while avoiding the more dogmatic, and even mechanical, underpinnings of traditional economic analysis. In this article we trace the development of this new 'options-based' approach and chart out the path for further research. It warrants, we believe, a voice in the dialogue on economic evaluation.

\section{KEYWORDS: COST BENEFIT ANALYSIS, EVALUATION, STAKEHOLDERS, REAL OPTIONS}

\section{L'évaluation économique et l'âge de l'incertitude}

L'évaluation a pour but principal de soutenir les jugements de valeur concernant les politiques et les programmes, mais les évaluateurs sont loin d'être d'accord sur le moyen d'accomplir cette tâche. Les méthodes traditionnelles de l'analyse coûts-avantages se sont révélées insatisfaisantes tandis que les enquêtes qualitatives auprès des parties prenantes, qui ne sont pas ancrées à la théorie économique, inspirent peu de confiance. Bien qu'il ne soit guère possible de concevoir une méthodologie acceptée par tous, la théorie économique a récemment connu des développements qui encouragent une nouvelle interprétation. L'approche proposée dans cet article est une modification de l'analyse des coûts et des avantages sociaux; cette méthode a l'atout de représenter les valeurs des parties prenantes tout en évitant les aspects plus dogmatiques et mécaniques de l'analyse économique traditionnelle. Cet article décrit cette nouvelle approche fondée sur les options réelles et indique le chemin pour continuer la recherche.

Mots-clés: analyse coûts-avantages; évaluation; parties prenantes; options réelles.

\section{Values, Valuation and Evaluation and Development Projects}

The definitions of the noun 'value' in the evaluation terminology tend to be themselves valueloaded, in that they evoke a concept of 'worthiness'; this is inevitably related to a theory of formation or foundations of values and may require ethical, political and ideological principles. Thus it tends also to be controversial and ambiguous. Nevertheless, values, valuation and evaluation are terms that have become increasingly popular among professionals, scholars and decision-makers. In this paper, we will eschew the question of 
what is value and concentrate on the more mundane problems of valuing and evaluating. In our terminology, valuing is the process of assigning a measure of worth to objects, whereas evaluating is a broader process of assessing the merits and the demerits of an action to provide guidance for decision-making. Evaluation does generally attempt to incorporate valuation, but it may not always succeed. As Dasgupta $(2001$, p. 1) puts it: '...we value when comparing objects and we evaluate when comparing the relative merits of actions'. In economics 'the valuing of objects and evaluating of policies is only a means to measure ...(wellbeing) and to discover ways of improving it'.

Two things are important about evaluation. Firstly, this term does not cover only economic issues, since philosophers and social scientists have also much to say on the matter (Trochim, 2005). Taken as a whole, economic evaluation aims to be both scientific and managementoriented. Secondly, the apparent failure of many development projects has made social scientists and development-project practitioners increasingly aware of the importance of involving stakeholders in the evaluation process. The evaluation tends to divide the evaluators and the evaluated into two sets of subjects when analysing the complex issues. The evaluated might be the proponents and/or the implementers of a policy or a programme, whereas the evaluators often act on behalf of other stakeholders, such as the government, other institutions or the intended beneficiaries.

The broader purpose of evaluation is to construct and provide judgements about facts and values (Dasgupta, 2001, p.3) to guide choice and action. Policy-makers have at times advocated complete discretion in this regard, but there are also longstanding attempts to identify meaningful methodologies for forming judgements. For example, peer evaluation is virtually ubiquitous in the scientific community today and is qualitative by its very nature. Many other types of evaluation, such as score cards and 'weighing up the evidence' to identify best practices, are also qualitative. Evaluation by quantitative techniques, widely used in all natural sciences and in economic evaluation, is almost entirely confined to the statistical model of hypothesis testing.

The term 'economic evaluation' is also ambiguous. It denotes making informed judgements about an action on economic grounds. It also means the set of analytical techniques characterising some phases of the appraisal process. Theoretical literature supporting the modern practice of economic evaluation is, however, rather specific; it is based on 'new welfare economics' - an attempt at both evaluating and establishing evaluation criteria for policy changes by a government in a less than perfect economy (see, for example, Koopmans, 1957, Meade, 1964, 1973 and Mirrlees, 1969, 1971), but in the broader context of general equilibrium theory. The resultant evaluation model is quantitatively oriented, based on the firm foundations of neoclassical economics. It has some links with planning literature, but no connection with other branches of economic theory, including Keynesian macroeconomics and institutional economics.

This model is generally known as cost-benefit analysis. Its most systematic application has been promoted by international financial institutions, chiefly by the World Bank. However, it has attracted criticism ever since its first application, because of its dependence on a rather narrow theoretical foundation, on the relative obscurity of its techniques and practices and on the quantitative requirements for data and calculations. Its contrast with other social sciences is also related to its institutional viability. The idea that project selection and implementation could fail because a cost-benefit analysis encourages narrow-mindedness in evaluators found subtle and persuasive support in Albert Hirschman's work. Some of his concepts challenge the hypotheses of the ex-ante economic evaluation. For example, according to Hirschman (1967), because of its overly rational, ex-ante approach, a cost-benefit analysis tends to overlook the side effects of the project, even though these may be more important than the direct effects (the 'centrality of side effects'). The cost-benefit analysis also tends to ignore the hidden rationality that emerges in the project-implementation process ('the hidden hand', 
Hirschman, 1982). More generally, one of Hirschman's main models (1972) argued that social systems, including programmes and projects, are designed to respond to participatory ('voice') and market ('exit') behaviour. When applied to development projects, if the main stakeholders are not actively engaged the economic evaluation could became a simple tool to give ex-post respectability to choices based on purely political guidelines, organisation pressures and institutional goals. As one of Hirschman's followers wrote:

....so much of economic analysis of projects in development assistance and other public sector entities either amounts to a post hoc rationalization of decisions already taken, or is not allowed to focus on the relevant alternatives, and hence almost always comes out in favor of the project on hand. (Tendler, 1975, p. 95).

The economic evaluation is not sufficiently participatory to tap fully the responsiveness of institutions to the stakeholders' 'voice' rather than to the 'exit'. On the other hand, it is not sufficiently strong to exercise the 'exit' option when the project is not worth undertaking.

The difference in the economists' approach to the evaluation from that of other social scientists, however, was not limited to the participation issue. In Rowlands' (1991) useful summary of different approaches to the evaluation of social-development projects, we find that the 'traditional' cost-benefit analysis approach involves:

- a search for objectivity, through standardised procedures, with values often reflecting the evaluator's priorities;

- over-reliance on quantitative measures, whereas qualitative aspects tend to be ignored because difficult to measure;

- a high degree of managerial control, whereby managers can influence the questions being asked, with little input from other stakeholders;

- professional evaluators are usually professionals, in the belief that this will increase objectivity, but prompting a possible negative perception by those 'being evaluated'.

The proposed alternative is:

- to view evaluation as an integral part of the project and as a process of development and change with interaction among different subjects and recognition of stakeholders' subjectivity;

- to focus on dialogue and enquiry rather than on measurement;

- to approach evaluation as an 'empowering process', with a key role given to negotiations, rather than as a control by an external body;

- to consider the evaluator as a facilitator rather than as a neutral outsider.

These points highlight the crux of the objection to the traditional economic approach to evaluation: the neglect of the nature of evaluation as a process and, above all, of its subjective dimension. At the same time, however, no social science other than economics or related disciplines has proposed an alternative, theoretically-based and quantitative model of evaluation. The gap between the qualitative and quantitative evaluation thus also reflects that between economics and the other social sciences. This article attempts to narrow the gap.

\section{The 'Golden Age' of Economic Evaluation}

In retrospect, the $1970 \mathrm{~s}$ and the $1980 \mathrm{~s}$ can be viewed as 'the golden age' of economic evaluation. At the beginning of the 1970s, the OECD and UNIDO published two landmark manuals (OECD, 1972; Dasgupta, Marglin and Sen, 1972), almost simultaneously, which gave rise to two best-sellers on the subject (Little and Mirrlees, 1974; Squire and van der Tak, 1975). More significantly, the World Bank and major international financial institutions incorporated the manuals' approach into their operational procedures and practices and carried out experimental research. The testing concerned especially the area of economic evaluation of the income-distribution implications of programme and project choices. The 'shadow prices' derivation techniques stemming from the approach have now became standard fare in operational practices in both developed and developing countries as well as in planned and market economies. The methodology, the techniques and the procedures are generally known as the 'social cost benefit analysis' (SCBA) approach. 
The main contribution of the manuals was not theoretical but methodological and procedural: to develop a comparatively simple and transparent approach to computing the economic and social opportunity cost (viz. the opportunity cost to a country or to a society) of a project or of other social actions. The SCBA approach entails: (i) reference to international markets to estimate opportunity costs and (ii) derivation of 'national parameters' and 'variable weights' from an often implicit objective function so as to capture normative policy objectives and constraints. The main advantage of SCBA was that it produced a set of procedures easy to teach and to apply. Procedural literature is flourishing worldwide but the basic approach has not changed since the 1970s-1980s (Belli, Anderson, Barnum, Dixon, Tan, 2001; Wallisser 1990; Weiss, 1998). At that time, the academic and professional debate on economic evaluation focused on several SCBA issues, albeit it mostly dealt with the relative advantages and disadvantages of another approach - 'the effects method'- then being manualised, as well as the possibility of combining both approaches (Balassa , 1977a and 1977b; Chervel 1995). It was, however, generally agreed that the implementation of SCBA would, in the medium and long run, help to improve resource allocation and promote better governance. This last point was highlighted because SCBA promised to provide systematic and transparent documentation for decision making, to encourage accountability and to enhance participation and democratic debate on public issues.

Even more important than the academic and professional debate was the widespread application of SCBA to project analysis. Normally, major shortcuts were applied in the methodology for defining 'parameters' and 'shadow prices'. Variable weights, however, were utilized only occasionally for the economic analysis of income-distribution issues. The World Bank tested the full application of SCBA (including distributional aspects and the application of 'variable weights') for nearly seven years. More generally, in the words of a recent review of the World Bank's view of evaluation (Picciotto, 1994, p.2),

... economic evaluation was considered part of the contractual framework which drives public choice. Of course, the behavior of agents cannot always be reduced to the fulfilment of precise contractual obligations. All the contingencies and uncertainties of real life cannot be anticipated in advance. Many contracts are inevitably 'incomplete' and it is often necessary to rely on general policies to provide participants to a collective enterprise the flexibility they need to deal efficiently.

\section{The Sunset of Economic Analysis of Policy, Programmes, Projects and Governance}

The sun started setting between the end of the 1980s and the beginning of the 1990s. There were various reasons for this:

- A broad change in priorities after the debt crisis of the 1980s (Pennisi and Scanni, 1991), with increasing focus on large transfers of capital flows rather than on the evaluation of programmes and projects.

- The change in the overall socio-political context where, also due to international terrorism, unexpected changes and a pervasive uncertainty are the key elements (Sandler, 2004).

- A Washington consensus (Williamson, 1994, Basu, 2003) which appeared to deemphasize micro-economic analysis of the type applied in SCBA.

Evidence of weaknesses of the SCBA was given by a World Bank internal review which concluded that, using the Bank's own evaluation criteria, 37.5 percent of recently evaluated projects were unsatisfactory as compared with 15 percent in 1981. According to a more recent review, (Knudsen and Scandizzo, 2003), there are three reasons for the development community's disaffection with SCBA. First, SCBA has failed to develop a credible and practical link between projects and policies. Second, it has suffered from the increasing emphasis on fast conceived-fast disbursing lending. Third, it has failed to argue its own case by convincing governments and bankers of its validity, relevance and usefulness. 
At the beginning of the 1990s, there was a gradual demise in academic and professional journals devoted specifically or entirely to the economic analysis of programmes and projects. (Picciotto, 1999). Alongside this, programme and project evaluation became a central area of interest for sociologists, political scientists and organizational specialists - as also proved by the many comparatively new journals that sprang up (a comprehensive review of sociological and organizational-oriented evaluation literature can be found in Bezzi, 2003). The European Commission evaluation handbook (European Commission, 1999), which gives very limited space to economic analysis in general and does not refer at all to SCBA, is another example.

The emphasis on the sociological and organizational evaluation as opposed to the economic evaluation is also demonstrated by the myriad theoretical and practical studies on the sociological and organizational evaluation (Alkin and Ellet, 1990; Bussman, 1996; Eisner, 1985; Fetterman, Kaftarian and Wandersman, 1996; Greene and Caracelli 1997; OECD, 1997; Owen, 1998; Palumbo, 2001; Scriven, 1991; Stake, 1995; Stern 1995; Tendler 1992; UNDP 1997; Wholey 1992 and Wolf 1987). The attempt to construct an interdisciplinary debate led to the creation of the journal Evaluation, almost concurrently with the demise of the quarterly Project Appraisal, for many years the most popular review on economic evaluation.

Why did the non-economic evaluation flourish and did it have a positive effect on decision making? Answering these two questions goes much beyond the scope of this article. We can note, however, the pragmatic value of the sociological and organizational forms of evaluation, with their 'logical framework' underpinned by experience and common sense, easily understood without any specific technical background. Albeit their intrinsically nonquantitative nature exposes them to other types of manipulation, these forms of evaluation appear less prone to the 'number fudging' practices of cost-benefit analysis. Finally, they could claim to generalise and make operational some basic economic concepts, such as the 'objective function' in multicriteria analysis, a feat that cost-benefit practices were not able to accomplish.

\section{A Fresh Start: Toward a New Model of Evaluation}

The problem of evaluation in economics has traditionally confronted two interconnected issues: (i) how to estimate the value of an object (the 'valuation' issue), (ii) how to form judgements on the actions to take for the formation of value (the 'value-creation' issue). The two questions are related in many ways. First, valuing something is the necessary startingpoint of any analysis of its value-creation function or potential. Second, value reflects willingness-to-pay; in turn, this is justified by the creation of utility or value for the potential acquirer. Third, the sources of value lie both in the desire to use a good or a service or to hold on to it for other reasons ('non-use values'), including the expectation that its value may increase. Fourth, rights and responsibilities in a modern society are regulated by contracts; they almost invariably imply that their object has a value contingent upon their successful completion.

Some of the fundamental principles underpinning these issues have only recently been clarified. Of these, two main theoretical advances stand out. They concern the role of rights, or 'entitlements', and the importance of non-use values. On the first issue, it has become increasingly clear that value creation and market exchange do not concern goods and services per se, but a variety of rights, or 'entitlements'. The rights and 'entitlements' may include not only 'use rights' concerning goods and services but also 'non-use rights'. The means whereby rights are exchanged and become the basis for value creation depend on successfully negotiating and implementing contracts, which are, by their very nature, incomplete and contingent on the state of the world in an uncertain environment. Most rights exchanged in the markets via contracts concern 'non-use rights', that is rights to hold, to dispose, to alienate, to access, to exclude and to control, without necessarily consuming or utilizing, the goods. 
According to Coase (1988), the firm was created in an attempt to re-organize contracts of exchange as an alternative to the market, economizing on transaction costs. The value of the firm thus derives from a peculiar configuration as well as from the practical content of 'rights'. This depends on its 'dedicated hierarchical nature' and the assignment of different 'rights' to its various stakeholders (Ackerman and Alstott, 1999), with ownership and control embedded in shareholders' residual 'rights'. Because all economic activities can be interpreted as 'enterprises', i.e. business ventures, this approach and its developments have brought about a quiet revolution in value assignment issues. It has forced economists to face squarely the plurality and heterogeneity of the subjects creating the values to be estimated, an issue that had been neglected in economic evaluation in general and in SCBA in particular.

In Law Schools and in the legal profession, a 'new theory of corporations' is now emerging (Stout, 2004). Legal experts traditionally distinguish corporations from unincorporated business forms by such corporate characteristics as limited shareholder liability, centralized management, perpetual life and freely transferred shares. The 'new theory' adds a fifth, oftenoverlooked, characteristic of corporations: their capacity to lock in equity investors' initial capital contributions by making it far more difficult for those investors subsequently to withdraw assets from the firm. Like a tar pit, a corporation is much easier for equity investors to get into than to get out of. The 'capital lock in' by a plurality of concerned parties is the basis for the 'contingent wealth' of the firm. For each concerned party, the 'valuation' issue and the 'value-creation' issue are inevitably related to the 'opportunities' opened up and/or foregone through the 'capital lock in'. 'Valuation' and 'value creation' differ from party to party, depending on each party's 'capital lock in', specific objectives and constraints.

In economic evaluation, a crucial point about the various parties forming an enterprise is the contingent nature of the contracts binding them to one another, as in the 'new legal theory' outlined above. The value of these contracts is, as a result, a stock of 'contingent wealth'. In the evaluation of firms and of programmes and projects, it has always been recognized that the Discounted Cash Flow (DCF) expressed value as a stock of wealth. Its valuation, however, was always considered as an alternative to the net-worth measures based on balance sheets and accounting values. As a consequence, DCF methods, including SCBA, ended up concentrating on flows of incomes and consumption as the sole sources of wealth. This has caused a neglect of both assets and liabilities not readily expressible as the present values of future cash flows and, more seriously, of many intangible elements, including goodwill and risk.

Focusing on competing claims, as well as on the linkage of claims to stakeholders' specific 'capital lock in', implies that the evaluation of any enterprise should be approached from the point of view of several agents and that its basis should be wealth, not solely or primarily income. According to the 'genuine investment theory', the basis of wellbeing is wealth in the form of human and non-human capital: 'A country's wealth is the social worth of its capital assets. It is a measure of the nation's opulence, subject to a well-defined set of qualifications, it is simultaneously a measure of social wellbeing.' (Dasgupta, 2001, p.146).

In this paper, we focus on only two main principles of a wealth-based evaluation: (i) the value of 'rights' within a context of good governance and, (ii) the role of 'rights' as opportunities that constitute contingent wealth.

\section{Opportunities and 'Contingent Wealth'}

The focus on 'rights' and institutions has progressively re-oriented the economics of evaluation in a further important sense: it has suggested an imaginative approach to the question of uncertainty and risk. From an institutional point of view, the concept of uncertainty is directly related to the incomplete nature of contracts. Because of the multiplicity of possible states of nature, any contract faces two separate problems. It has to include clauses that establish contingent conditions, i.e. conditions that exist in some states of 
the world and not in others. On the other hand, it cannot include a clause for every possible contingency. Uncertainty thus derives from the fact that contract implementation may be either jeopardized or helped by unforeseen circumstances. Risks, on their part, are the consequences of the possible values that the rights of a party involved in the contract may assume as a result of a change in circumstances (Knudsen and Scandizzo, 2005a). Risks and opportunities, on the other hand, are created by embedding uncertainty in contracts between individualized parties, thus privatizing it through the contractually-organized exchange of rights. Contracts, therefore, are a way through which private and public parties take positions to exploit the opportunities, at the cost of corresponding risks, offered by uncertainty. Uncertainty can thus be interpreted, in the spirit of the Coase theorem, as an externality that can be eliminated through the creation of 'contingent markets'. These provide, through different contractual structures, the means by which the externality is internalized, via the assignment of property rights, to individual parties - an area being investigated by the "new institutional economics' (Williamson, 2000). The incentive for doing so is given by opportunities that can only be created under uncertainty.

We reach thus the core of some of the most interesting developments in welfare, political economy and justice theories. What is an opportunity and how can we measure it in an economic context? To answer this question, firstly we notice that a basic economic concept frequently used in evaluation is 'opportunity cost', a notion that captures the idea that the value of a given resource depends on its alternative, possible uses. In this context, 'opportunity' simply means that the resource considered is the object of competition from alternative uses, and any particular selection of one of these necessarily foregoes the other possibilities. Even though the concept implies that the value of a given resource depends on the alternatives foregone, and, among these, on the next best one, it does suggest a more daring thought: the source of value is not to be found in the actual productivity of a resource, or in the utility of a good or service, but rather consists of a more abstract property of potential gains or losses. These potential gains and losses denote concrete alternatives that could be exploited with a significant likelihood in some states of the world; in economic evaluation, they deserve to be identified and quantified.

Along these lines, a further use of the word 'opportunity' is found in the theory of contracts, where 'opportunistic behaviour' is characterized as the exploitation on the part of selfish agents of the 'opportunities' permitted by incomplete contracts. In this case, 'opportunity' indicates that an action becomes suddenly profitable for one of the parties during the implementation of the contract, either because of its incomplete nature, or because of insufficient monitoring or incentives. Exploiting the 'opportunities' offered by circumstances is thus seen as the capacity of 'agents' to be flexible in response to the changing conditions of the environment, in a context of uncertainty.

We can also find the abstract notion of 'opportunity' as positive potential in the theory of optimal decision making. A 'choice set', in fact, is nothing but a collection of alternative 'opportunities' for action: the larger the set, the more numerous are the opportunities and the better off, coeteris paribus, is the condition of the rational decision-maker. Albeit this conclusion has been challenged by recent psychology research (Schwartz, 2004), on the grounds of pre- as well as post-decision regret and decision anxiety, the widening of the choice set is certainly positive in situations of poverty or disenfranchisement. Related to the widening of the opportunity (the choice) set, is the benefit accruing to consumers from the introduction of 'new' goods, or from quality improvements. In both cases, consumers' utility (and producers' profit) may be substantially enhanced by the provision of previously unavailable 'opportunities' to consume or produce.

However, it is in the welfare-theory field that the concept of 'opportunity' has assumed its most innovative meaning, mostly because of Sen's contribution (see, for example Sen 1997a and 1997b). According to Sen, 'opportunities' are the environment-generated counterpart of 
the subject-rooted concept of capabilities. Capability may be conceived as an asset that enables individuals to exploit opportunities. Individuals realise themselves by creating their own capabilities, by developing their raw capacities with education or exercise. Sen's analysis suggests that the concept of opportunity has a direct bearing on the question of 'rights' under uncertainty. An 'opportunity' is the faculty to take advantage of a situation, i.e. of a combination of circumstances that may occur in a particular state of the world. It does require at least one subject entitled, by virtue of an explicit or implicit contract, to exploit the potential advantage by taking some action. In other words, the combination of an 'opportunity' and the corresponding capability to exploit it is a 'contingent right' and, to the extent that its value can be recognised, directly or indirectly through exchange, it is a form of contingent wealth.

On reflection, the pervasive uncertainty in our world is such that all wealth may be considered contingent, in the sense that it gives rise to 'opportunities' to gain, which are dependent on the particular state of the world that happens to prevail. This concept is well captured in the 'theory of real options', which is the most rigorous proposal to date to give formal and quantitative body to the concept of 'opportunity' as a contingent right. In financial markets, 'an option' is the right, but not the obligation, to buy (in the case of a 'call' option) or to sell (in the case of a 'put' option), an underlying asset at an established price. Despite its simplicity, this definition, which identifies a specific set of financial instruments, can be extended to any form of contingent wealth. Any 'right' on an underlying asset, in fact, be it the ownership of physical capital, or the know-how of a particular technology, or any capacity for an action that may result in individual gain, can be interpreted as an 'option', in the sense that it gives the 'opportunity' to the holders to decide whether it is in their interests to implement the action to which they are entitled, given the circumstances that happen to prevail.

\section{A New Frontier for Economic Evaluation}

Accepting that 'rights' are the key feature of a modern economy is not enough to characterize a new theory and practice of evaluation. A second, no less important point is that 'opportunities' and, hence, 'uncertainty' are also crucial to understand how economic and financial values emerge from human activity. The concept of 'contingent wealth' and the associated concept of 'real options' are the main products of this thinking. The discussion in the previous paragraphs offers a new economic definition of the concept of programmes and projects. In addition, its suggests new ways of solving the issues left unresolved in the 1980s. It requires, however, a path to make this definition operational. and it has to be tested to see whether it is feasible and credible.

In a recent book (Pennisi and Scandizzo, 2003), we provide a new definition of programmes and projects. We start with the definition of what is a project, because programmes are normally seen as interconnected projects within a comprehensive set of goals and objectives. Also, and more significantly, SCBA was initially developed for project planning and evaluation; only later was it applied to programmes and occasionally to policies (Pennisi, 1999). In short, from the 1930 s to the 1970 s, projects and project planning were generally linked to physical-capital formation. In the 1970s, project planning and evaluation proposed a different notion of what a project is: in SCBA, a project is viewed as an instrument of economic policy, which may or may not entail physical-capital formation. Because it is an instrument of economic policy, it has to be evaluated on the basis of a set of social objectives and constraints with the aforesaid ramifications.

Our discussion yields yet another concept of a project: a project is seen as 'an economic policy opportunity' which may create or destroy other 'opportunities' for various groups involved in, or concerned with, the project - the stakeholders. This definition is broader than the previous ones, as it provides a framework to evaluate the build up of intangible capital 
(for path-breaking work on this subject, see Baruch, 2001) and suggests a better link between projects, programmes and policies.

Theoretical and practical studies of financial markets deal extensively with the evaluation of 'opportunities' and of 'opportunistic behaviour', mostly through 'options' theories and practices. In our book, as well as in our current research, conducted in collaboration with the World Bank and a number of Italian institutions (Knudsen and Scandizzo, 2004), we borrow heavily from some of these theories and practices as well as from the new frontier of law and economics. Our aim is to use real-option theory in combination with an array of best practices and experiments to build a new methodology for policy, programme and project evaluation.

\section{A Short History of Real-Options Theory and its Central Concepts}

As a field of research, real-options theory began in the 1970s when the analogy between the valuation of enterprises and investment and the pricing of financial options was realised (Merton, 1973). It received comparatively little attention from SCBA scholars, at the time more concerned with handling risks, uncertainty and irreversibility either through sophisticated mathematical tools such as the "Montecarlo simulation" (Pouliquen, 1970) or by correcting the discount rate (Hodder, 1986). In the 1970s, the real-option concept entered the area of policy and project evaluation: real options were seen as a part of investment spending, namely as a contingent contract with as many possibilities of gains (and losses) as the 'options' stemming from possible alternative courses of action originating from the policy or the project (Myers, 1977). Thus, the worth of an investment depended also on its components reflecting the evaluation of the options. From this initial intuition, a new path began, especially in corporate-investment analysis. It purported that the usual methods to value enterprises (based on capital asset pricing models or CAPM) consistently underestimate their market values because they take no account of investment opportunities and related options (Myers, 1977). It applied option pricing to project financing (Mason, Merton 1985) and to the interaction among options to be created and/or destroyed by the same investment (Trigeorgis, 1993). In the 1990s and in more recent years there has been a vast analytical development in the methodology (Kulatilaka, 1993; Dixit and Pindyck, 1994; Amran and Kulatilaka, 1999; Pennisi and Scandizzo, 2003; Knudsen and Scandizzo, 2005b).

In general terms, the application of real-options theory to policy, programmes and project evaluation respects the main premises of SCBA and utilizes SCBA's indicators - most significantly the Net Present Worth (NPW). This is an extension of SCBA and, in professional jargon, along with standard NPW (following standard SCBA methodology, technique and procedure), an "extended NPW" is computed. The main difference between standard NPW and extended NPW is that the latter includes not only the standard cash-flows but also the 'cash-flows' deriving from the 'options' pertinent to the 'with-the-project' scenario as well as to the 'without-the-project' scenarios. The policy, the programme or the project entails different sets of options for each category of stakeholders; some of the options are positive, whilst others are negative (liability options); positive options for a category of stakeholders could very well be negative options for other categories of stakeholders. Thus, it is essential to define the stakeholders and identify the options relevant to each category as well as the most significant possible scenarios in the 'with' and 'without' situations. Of all possible options in the 'without' situation, at least one is destroyed ('burnt' in professional jargon) if and when the policy, the programme or the project is carried out. In the 'without' situation, the policy, the programme and the project is one of the many options available to the decision-maker, as well as to the stakeholders.

Like options in financial markets theory and practice, in the 'without' situation the project is a 'call option' in that it provides the 'right' or the 'title' at a given price (the investment cost) to obtain an 'underlying value': the NPW as well as the NPWs of all the other options created and/or destroyed. The value of each option depends not only on the date by which it has be 
exercised but also upon the path to reach this date and thus all the intermediate dates. The value of each option depends on the expected NPW, the discount rate and the volatility (the variability of the expected net gain). The most significant options to be examined in deriving the 'extended NPW' turn out to be five: the option of (i) deferment, (ii) expansion, (iii) exit, (iv) suspension and (v) contraction.

Of these, option (i) and (ii) are 'call options' as they refer to 'the right' of delaying the start of the project or of expanding its scope at a later date. Option (i) is 'destroyed' when the project starts, option (ii) when the project's scope is expanded. Options (iii), (iv) and (v) are 'put options' as they refer to 'the right' of closing the project before its completion, or of suspending its implementation or of reducing its scope.

Because of the consideration of real options, the development of a project (policy, programme) is not a cycle, as in the standard procedures of the international financial institutions and of the European Commission, but a 'sequence': during the 'sequence' different options are created and destroyed, also 'compounded options' emerge (e.g. the burning or destruction of an option may create or burn other options). Some options can be exercised in line with the progress in project implementations; but the exercise of certain options is conditional not on project implementation but on previous action on other options. This latter category of options may be related to projects other than that under consideration; e.g. the option to build a road could be conditional on the building of a bridge for crossing a river. The sign (positive or negative) of interaction between several options depends on their typology (put or call) as well as on the sequence in which they appear. The degree of interaction depends on the typology as well as on the temporal distance between the 'rights' to exercise them (Knudsen and Scandizzo,2005).

\section{Operational Implications: A Few Specific Points}

A key implication of the new approach to policy, programme and project evaluation outlined in this paper is the central role of stakeholders' analysis and, hence, of decentralized decisionmaking. For many years, stakeholder analysis has been a key feature of non-economic approaches to evaluation, especially in the organizational and sociological disciplines (Bezzi, 2003, Stame, 1998). Attempts to draw a converging path towards sociological and economic evaluation (Picciotto, 1999) have rested mostly on qualitative considerations and have not brought about a new evaluation methodology.

In the proposed new approach, stakeholders' analysis is not intended to explore only the stakeholders' viewpoints on the project, but aims at identifying a corporate structure of the project: assets and liabilities of its stakeholders are the opportunities created by the project (the 'options', including the 'liability options') and a form of contingent wealth. Methodologically, this calls for a strengthened financial analysis; not only in the sense that more attention is paid to the benefits and costs accruing to the different stakeholders, but also, and more cogently, because option theory provides an integrating framework to appraise the contingent wealth of the subjects involved. The fact that the project creates and destroys options for different parties provides a way to account for benefits and costs based on the gains and losses accruing to the subjects involved. In this context, even a straight public infrastructure project, such as a bridge or a highway, can be entirely evaluated through the opportunities that it creates (or destroys) for any class of stakeholders whose entitlements are directly or indirectly affected by the project.

An 'options-based' analysis expands significantly on traditional practices for financial analysis, because is requires the building of quantitative and qualitative scenarios. This should be done, however, at the pre-feasibility level, in much more succinct terms than standard practice. The purpose would be to assess, on the basis of explicit and implicit contracts and related 'capital lock in', the capacity of a project to create value through changing the rights and opportunities for a set of interested parties. Thus, for example, in the new strategic plans 
financed by the European Union to revitalise medium-size towns, evaluators are experimenting with summary financial analyses. These are used to identify the main project scenarios, the stakeholders and the best communication and accounting techniques, to select and evaluate clusters of projects as alternative courses of action to be promoted by public decision-makers.

Another recent application of these ideas is the pre-feasibility study conducted by the authors (Pennisi and Scandizzo, 2004) on the introduction of terrestrial digital television (T-DBV) in Italy. The economic evaluation has involved interaction with Italian communication authorities, companies, research institutes and consumers and the financial analysis has been performed on the basis of aggregate cash flows for each group of stakeholders. The main options identified through direct interaction with the stakeholders have enabled the project to be analysed on the basis of alternative configurations, likely scenarios and time-dependent strategies. The project, while attractive under many aspects, involved a number of key uncertainties, such as the rate of growth of demand and consumers' reaction to the new interactive contents of T-DVB. The process of evaluation was thus instrumental in showing up these uncertainties and clarifying the different stakeholders' perceptions as well as providing for their option-based measure. It concluded by estimating a positive extended net present worth for the project, but asserted that, before a final appraisal could be formulated, a second phase should be developed with a more intensive interaction with the stakeholders.

As another example, in a larger-scale experiment conducted at the World Bank (Knudsen and Scandizzo, 2003, 2005), the methodology of real options was applied to several projects, some of which had been rather controversial throughout their evaluation cycle. One of these projects concerned a power plant in Vietnam. Four project scenarios were debated with the main stakeholders (government agencies and the World Bank) and subsequently analysed with the real-option methodology. For each alternative, several options were framed and estimated, with fuel prices and gas availability as the main sources of uncertainty. The analysis identified the most cost-effective alternative. More significantly, however, the development of the analysis showed how the real-option methodology led to a different development and study of the project alternatives from that of standard World Bank practices. First, the interaction and debate among the research team, the project team and the other interested parties was a much more intensive stage of the project study than in the traditional methodology, and led also to a subsequent in-depth study of this project typology. Secondly, the emphasis on uncertainty, gas availability and price risk focused the search of alternatives on a few critical economic and financial variables rather than on pure technical and engineering aspects. Thirdly, identifying the options added the key elements of flexibility and expansion to the technical characteristics of the project alternatives identified.

These three examples show that financial analysis will tend to become more complex. Even though it will require more information, this information will not be difficult to obtain because it often consists of summary estimates of possible net benefits in alternative scenarios and related volatilities. Furthermore, the consideration of dynamic uncertainty and option values will accentuate the simulative aspects of project evaluation, thereby providing a better analysis of its strengths and weaknesses by exploring the effects of alternative world states. The increased complexity of the risk analysis, finally, may be compensated by simpler cashflow models of stakeholders' budgets. Their details become less important as the focus of the analysis shifts from the determination of cash flows to the options that projects generate for the stakeholders.

The new emphasis on the evaluation from the point of view of a plurality of stakeholders raises a number of methodological problems, which call for full exploration in a research agenda, i.e.: 
- The stage of the project cycle at which to carry out an analysis, which will tend to be more elaborate and costlier than standard practices in terms of information and related resources requirements.

- The drawing of the 'boundaries' to identify stakeholders and to select the key subset which calls for a full 'option-based' financial analysis.

- A rigorous and, at the same time, sufficiently simple, approach to the construction of alternative scenarios and related options.

- The consideration of uncertainty as distinct from subjective risk, and the dichotomy between 'credibility' and 'feasibility' as well as between 'centralized' and 'decentralized decision-making'.

\section{Some Conclusions}

While evaluation is a central point of rational behaviour, SCBA can be seen, as one of the referees of this article aptly described it, as '.. the thin end of the wedge that economists used to trespass into the domain of development financing'. At the same time, SCBA has also the effect of increasing interest in governance, first through planning and then gradually through the development of management methodologies, decentralized decision techniques and incentive contracting. Finally, SCBA is also prompted by a deeper demand for rationality. According to Sen's (2000) incisive epitaph, cost-benefit analysis responds to the basic need of not wanting only to know whether something is right, but also why it is right.

In this paper, we have argued that some of the traditional foundations of value and evaluation in economics have been recently subverted by a quiet revolution. This revolution concerns the nature and the composition of the market, which is increasingly seen as a milieu of contracts and rights, rather than a place where goods and services are exchanged. It concerns also the structure of value, with non-use values gaining increasing attention in determining opportunity costs and willingness-to-pay benefits. It concerns opportunities and risks, seen as a form of non-use values generated by the attempt of interested parties to gain from the pervasive uncertainty affecting the environment and the contractual arrangements necessary to obtain economic action.

In this context, a new methodology, based on the theory of real options, has been developing in the business field, mainly to incorporate 'management flexibility' in corporate procedures on capital budgeting. Only slowly and with many difficulties is the idea being accepted that these techniques may be of assistance in re-thinking SCBA and re-launching economic evaluation in public decision-making. At the same time, it should be clear that the issue involved is not only that of updating the traditional methodologies nor is a simple extension of the techniques of real-option pricing sufficient to give a new impulse to the economic evaluation of policies and projects. Rather, updating, revising, and refurbishing traditional SCBA in the light of the new developments should go hand in hand with the integration of welfare economics with institutional economics and real-option theory. This task demands a great commitment on the part of researchers, but also informed interest and support from policy- makers and institutions.

\section{References}

Ackerman, B. and A. Alstott (1999) The stakeholder society. New Haven: Yale University Press.

Alkin, M.C. and F.S. Ellet Jr. (1990) 'Development of Evaluation Models', in H. J. Walberg and G. D. Heartel (eds.) The International Encyclopedia of Educational Evaluation, New York: Pergamon Press.

Amran, M. and N. Kulatilaka (1999) Real options. Boston: Harvard Business School Press. Balassa, B. (1997a) 'The "effects method" of project evaluation once again'. The Oxford Bulletin of Economics and Statistics 39(4): 345-353. 
Balassa, B. (1977b) Méthodologie de la recherche en Afrique de l'Ouest. Washington, DC: Banque Internationale pour la Reconstruction et le Développement. Unpublished manuscript.

Baruch, Lev (2001) Intangibles: Management, Measuring, Reporting. Washington, DC: Brookings Institution Press.

Basu, K. (2003) 'Globalization and the Politics of International Finance: The Stiglitz Verdict', Journal of Economic Literature 41(3): 885-899.

Belli P., J.R. Anderson, H.N. Barnum, J.A. Dixon and J.P. Tan (2001) Economic analysis of investment operations. Analytical tools and practical applications. Washington, DC: World Bank Institute Development Studies.

Bezzi C. (2003) Il disegno della ricerca valutativa- Nuova edizione rivista ed aggiornata. Milano: Franco Angeli.

Bussman, W. (1996) 'Democracy and evaluation's contribution to negotiation, empowerment and information: some findings from Swiss democratic experience'. Evaluation 2(3): 307320.

Chervel, M. (1995) L'évaluation économique des projets. Calculs économiques publics et planification. Paris: Publisud.

Coase, R. H. (1988) The Firm, the Market and the Law. Chicago: The University of Chicago Press.

Dasgupta, P.S., S. Marglin and A. Sen (1972) Guidelines of project evaluation. Vienna: UNIDO.

Dasgupta, P.S. (2001) Human Well Being and the Natural Environment. New Delhi: Oxford University Press.

Dixit, A.K. and R.S. Pindyck (1994) Investment under uncertainty, Princeton: Princeton University Press.

Eisner, E.W. (1985) The art of educational evaluation: a personal view. London: The Falcon Press.

European Commission (1999) Evaluating socio-economic programmes, MEANS Collection, Luxembourg: Office for Official Publications of the European Communities.

Fetterman D.M., S.J. Kaftarian and A. Wandersman (eds.) (1996) Empowerment evaluation: knowledge and tools for self assessment and accountability. Thousand Oaks, CA: Sage.

Greene, J.C. and V.J. Caracelli (eds) (1997) Advances in mixed-method evaluation: the challenge and benefits of integrating diverse paradigms. New Directions for Program Evaluation 74, San Francisco, CA: Jossey-Bass.

Hirschman, A. (1967) Developments Projects Observed. Washington, DC: The Brookings Institution.

Hirschman, A. (1972) Exit, Voice and Loyalty, Cambridge, MA: Cambridge University Press. Hirschman, A. (1982) 'Rival interpretations of market society: Civilizing, destructive or feeble?'. Journal of Economic Literature 20(4): 1463-1484.

Hodder, J. (1986) 'Evaluation of manufacturing investments: a comparison of US and Japanese practices' Financial Management 15(1):17-24.

Knudsen, O.K. and P.L. Scandizzo (2003) Evaluating Public Policies and Projects Under Uncertainty Through the Application of Real Options. A Research Proposal, The World Bank. Unpublished manuscript.

Knudsen O. K. and P.L. Scandizzo (2004) Evaluating Public Policies and Projects Under Uncertainty Through the Application of Real Options, Mid term research report, The World Bank. Unpublished manuscript.

Knudsen, O. and Scandizzo, P.L. (2005a) 'Bringing Social Standards in Project Evaluation under Dynamic Uncertainty’. Risk Analysis 25(2): 457-466.

Knudsen, O.K. and P.L. Scandizzo (2005b) The Artful Face of Uncertainty: How to Manage Opportunities and Threats, Washington, DC: The World Bank, (forthcoming). 
Koopmans, T.C. (1957) 'The price system and the allocation of resource', in T.C. Koopmans (ed.) Three Essays on the State of Economic Science. New York: Mac Grow and Hill.

Kulatilaka, N. (1993) 'The value of flexibility: the case of dual fuel-industrial boiler'. Financial Management 22(3):271-279.

Little, I.M.D. and J. Mirrlees (1974) Project appraisal and planning for developing countries. London: Heinemann.

Mason, S.P. and Merton R.C. (1985) 'The role of contingent claims analysis', in E. Altman and M. Subrahmanyan M., Recent advances in corporate finance, Homewood: Richard Irwing.

Meade, J. E. (1964) Efficiency, Equality and the Ownership of Property. London: George Allen \& Unwin.

Meade, J.E. (1973) The Theory of Externalities. Geneva: Institute Universitaire de Hautes Etudes Internationales.

Merton, R.C. (1973) 'The relationship between put and call prices: comment'. Journal of Finance, 28: 183-184.

Mirrlees, J.A. (1969) 'The Evaluation of National Income in an Imperfect Economy'. Pakistan Development Review, 9:11-13.

Mirrlees, J.A. (1971) 'An Exploration in the Theory of Optimal Income Taxation'. Review of Economic Studies, 38(April):175-208.

Myers, S. (1977) 'Determinants of corporate borrowing'. Journal of Financial Economics, 5(2): 147-175.

OECD, Organisation for Economic Co-operation and Development ( 1972) Manual of industrial projects analysis in developing countries. Paris: OECD.

OECD, Organisation for Economic Co-operation and Development (1997) Promouvoir l'utilisation de l'évaluation de programme. Paris: OECD.

Owen, J. M. (1998) 'Towards a theory of negotiations in evaluation'. Evaluation News and Comment 7(2): 32-35.

Palumbo, M. (2001) Il processo di valutazione. Milano: Franco Angeli.

Pennisi, G. (1999) 'Il manuale degli investimenti pubblici quindici anni dopo' in R. Camagni and V. Fazio (eds.) Politiche locali, infrastrutture per lo sviluppo e processi d'integrazione euro-mediterranea, pp. 245-260. Milano: Franco Angeli.

Pennisi, G. and P.L. Scandizzo (2003) Valutare l'incertezza - L'analisi costi benefici nel 21 simo secolo. Torino: Giappichelli.

Pennisi, G. and P.L. Scandizzo (2004) La transizione alla televisione digitale terrestre (DVBT) in Italia, Roma: Fondazione Ugo Bordoni. Unpublished manuscript.

Pennisi, G. and G. Scanni (1991) Debito, crisi e sviluppo. Venezia: Marsilio.

Picciotto, R. (1994) 'Visibility and Disappointment: The New Role of Development Evaluation', in Lloyd Rodwin and Donald A Schön (eds.) Rethinking the Development Experience. Washington DC: The Brookings Institution.

Picciotto, R. (1999) 'Towards an economics of evaluation'. Evaluation 5(1): 7-22.

Pouliquen, L. (1970) Risk analysis in project appraisal. Baltimore: The Johns Hopkins University Press.

Rowlands, J. (1991) 'How do we know it is working? The evaluation of social development projects' in F. Rubin (1995) A Basic Guide to Evaluation for Development Workers. Oxford: Oxfam.

Sandler, T. (2004) Global Collective Action. New York: Cambridge University Press.

Schwartz, B. (2004) The Paradox of Choice: Why More is less, New York: HarperCollins Pub.

Scriven, M. (1991) Evaluation Thesaurus. Newbury Park, CA: Sage.

Sen, A.(2000) 'The Discipline of Cost-Benefit Analysis'. The Journal of Legal Studies 29(2): 931-952. 
Sen, A. (1997a) Choice, Welfare and Measurement. Cambridge, MA: The Harvard University Press.

Sen, A. (1997b) Resources, Value and Development. Cambridge, MA: The Harvard University Press.

Squire, L. and H. van der Tak (1975) Economic analysis of projects. Baltimore: Johns Hopkins University Press.

Stame, N. (1998) L'esperienza della valutazione. Roma: Seam.

Stake, R.E. (1995) The art of case studies research. London, Sage.

Stern, E. (1995) 'Editorial'. Evaluation 1(1): 5-9.

Stout, L. (2004) 'On the nature of corporations', Law-Econ Research Paper n. 13. Los Angeles: UCLA School of Law.

Tendler, J. (1975) Inside Foreign Aid. Baltimore: The Johns Hopkins University Press.

Tendler, J. (1992) Progetti ed effetti. Napoli: Liguori Editore.

Trigeorgis, L. (1993) 'The nature of options interactions and the valuation of investments with multiple real options'. Journal of Financial and Quantitative Analysis 28(1): 20-39.

Trochim, W.M.K. (2005), Introduction to Evaluation. Unpublished manuscript available at http://www.socialresearchmethods.net/kb/intreval.htm

UNDP (1997) Who are the question makers? A participatory evaluation handbook. New York: United Nations.

Wallisser, B. (1990) Le calcul économique. Paris: La Découverte.

Williamson, J. (1994) The political economy of policy reform. Washington, DC: Institute for International Economics.

Williamson, O.E. (2000) 'The new institutional economics: taking stock, looking ahead'. Journal of Economic Literature 38(3): 595-613.

Weiss, C.H. (1998) Evaluation: methods for studying programs and policies. London: Prentice Hall.

Wholey, J.S. (1992) Professional Evaluation. Newbury Park CA: Sage.

Wolf, R.M. (1987) 'Educational evaluation: the state of the field'. International Journal of Educational Research 11(1): 1-143.

Giuseppe Pennisi is Professor of Economics at the Scuola Superiore della Pubblica Amministrazione - the Italian Government institution for middle and senior management civil service training. He has held management position in the World Bank and in the Italian civil service. His e-mail is giuseppe.pennisi11@tin.it.

Pasquale Lucio Scandizzo is Professor of Economic Policy at the University of Rome "Tor Vergata". He has held research and management positions in the World Bank, the Italian government and the non profit sector. His e-mail is scandizzo@uniroma2.it. 